\title{
Development of an Improved GMPPT Based on Scanning Method for PV System Operating under a Dynamic Partial Shading Conditions
}

\author{
Abdelilah Chalh ${ }^{1}$ (D) $\cdot$ Aboubakr El Hammoumi $^{1} \cdot$ Saad Motahhir $^{2} \cdot$ Abdelaziz EL Ghzizal $^{1} \cdot$ Aziz Derouich $^{3}$
}

Received: 26 April 2021 / Accepted: 17 September 2021 / Published online: 6 October 2021

(C) The Author(s), under exclusive licence to Springer Nature Singapore Pte Ltd. 2021

\begin{abstract}
Under partial shading conditions (PSCs), the P-V characteristic of a photovoltaic (PV) array becomes more complicated due to the presence of more than one power peak in contrast to normal conditions (without shading) where there is only one peak named Maximum Power Point (MPP). In this paper, an improved scanning method to track the Global Maximum Power Point (GMPP) with good tracking speed is proposed. The objective of this method is to reduce the response time by limiting the search interval of scan points in the scaning method, which makes the tracking of GMPP fast and efficient under PSCs. The effectiveness of the improved scanning method is verified using a PV simulator. The results demonstrated that the proposed method effectively tracks the GMPP under different PSCs and has excellent performance in terms of response time (1.4 s) and efficiency (99.50\%), which improves the efficiency and response time of the PV system by $0.55 \mathrm{~s}$. and $0.4 \%$, respectively, when compared to the scanning method.
\end{abstract}

Keywords Proteus $\cdot$ Improved scanning method $\cdot$ PV string $\cdot$ DC-DC boost converter $\cdot$ Ardouino

\section{Introduction}

1Over the last few decades, the solar energy field has attracted much attention from researchers [1-4]. As known in the literature, the PV module characteristics are highly dependent on environmental conditions such as solar irradiation, temperature, and wind, etc [5-8]. Solar irradiation can occur uniformly or non-uniformly on a PV array. The P-V characteristic of a PV array exhibits one peak under uniform irradiation conditions, and this peak is called the maximum power point (MPP). Tracking this MPP is always a critical issue in a PV system to maximize the power transfer from the PV array to the load. Over the past decades, many maximum power point tracking (MPPT) methods have been introduced to address this issue $[9,10]$. Among these methods, we found

Abdelilah Chalh

abdelilah.chalh@usmba.ac.ma

1 Innovative Technologies Laboratory, EST, SMBA University, $30000 \mathrm{Fez}$, Morocco

2 Engineering, Systems and Applications Laboratory, ENSA, SMBA University, Fez, Morocco

3 Industrial Technologies and Services Laboratory, EST, SMBA University, Fez, Morocco conventional methods such as perturb and observe $(\mathrm{P} \& \mathrm{O})$ Hill Climbing (HC), and incremental conductance (INC). However, the main drawback of these methods is that they have strong oscillations around the MPP in steady state, resulting in power losses of the available energy. To solve this problem, many researchers have tried to improve these conventional methods to reduce the steady-state oscillations. These improved methods are based on variable step size of duty cycle controllers [11, 12]. In addition, in [13], the authors presented a new sliding mode control for optimizing the power output of a stand-alone PV system. Although the implementation of conventional methods can be easily [14 15 16], they were unable to obtain the true MPP under PSC. Because, under the non-uniform solar irradiation caused by partial shading, the P-V characteristic of a PV array has several peaks. One of them is the global peak (GP) that represents the GMPP, and the others are the local peaks. In addition, due to the inability to track the real MPP under PSC, the power output of the PV array can be reduced by 10-70\% [17-21].

To address this problem, many GMPPT algorithms have been introduced in these references [22-28] to solve the complexness of the nonlinear behavior of PV characteristics and providing optimal solutions under partial or full shading conditions. Where we find most of them belong to soft computing (SC), evolutionary computation (EC), and swarm intelligence 
Fig. 1 Schematic of the entire PV system with the scanning controller

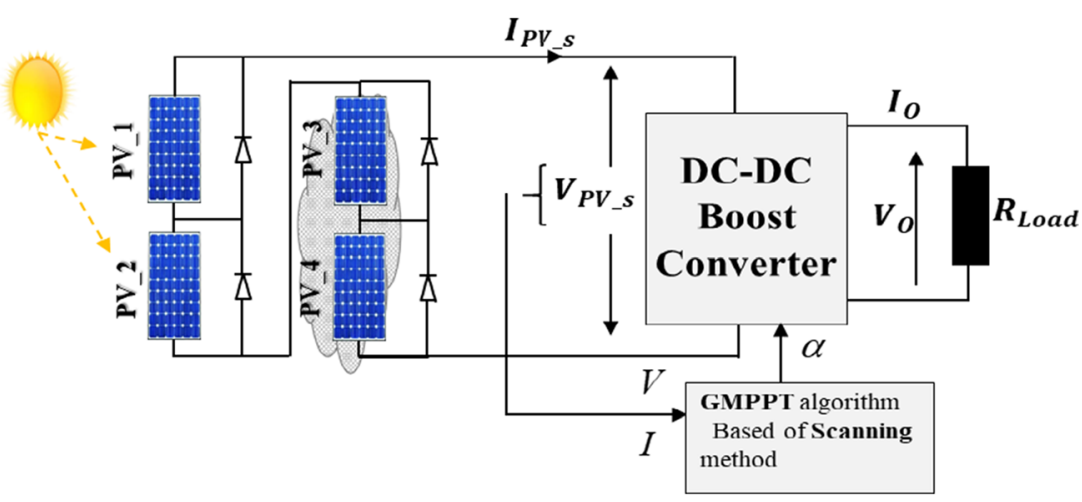

(SI) algorithms. Among the SC methods, we find the artificial neural networks (ANN). in [29] authors presented an application of an ANN for optimization of the out power of a PV alimented the dc motor. In addition, In [30] a detailed survey on ANN-based PV MPPT techniques was presented. From this survey, it turns the accurate results are good using ANN. But, when used a large number of hidden nodes this technique needs a longer computational time. Hence, it needs a complex hardware implementation.

In addition to that, several algorithms of intelligence artificial are introduced [31,32] in order to extract the maximum power of PV array with high efficiency under partial or full shading. But, these techniques might present a poor convergence rate and slow convergence time [33]. On the other hand, the SI methods have a good convergence rate and fast convergence compared to EC techniques $[34,35]$. Although these SI methods are better than the genetic algorithm (GA) and differential evolution (DE) methods. But, they have limitations. For example, the response time always linked to the initial placement of the particle. Which makes them inflexible and more complex [36]. However, the implementation of these methods is more complex [26]. To overcome these complexity found in the EC and SI methods, the scanning algorithm is introduced in [37] where all the MPP's values are stored in a microcontroller. Yet, this method is simple and easy to implement in low-cost microcontrollers. But, under storing all the possible MPPs, this method takes a long processing time. Because the scan is started from the point of the short-circuit current (ICC) to the open-circuit voltage (VOC) of the P-V characteristic. Hence, this techniques interrupt the system operation when scanning the entire control range between the VOC and ICC, which yields power losses.

The aim of this work is to present an improved scanning method in order to track the GP under dynamic PSCs. The objective of this method is to reduce and limit the scan interval, which avoids the passage through the short-circuit point of the P-V characteristics. In addition, it eliminates the open-circuit of the PV string during the scan interval in order to prevent disconnection of the PV system. All these modifications allow this proposed method to track the GMPP with good response time and high efficiency under dynamic PSCs. Moreover, the simple structure used in this proposed method will ensure reduced complexity of implementation, which reduces the cost of the PV system.

The rest of this paper is organized as follows: Section II presents the proposed methodology. The results and discussion are depicted in Section III. Finally, Section IV summarizes this work.

Table 1 The value of the irradiation taken for all simulation tests

\begin{tabular}{lllll}
\hline & {$[\mathrm{G} 1 \ldots \mathrm{G} 4]$} & MPP1 & MPP2 & GMPP \\
\hline STC & {$[1]$} & $80 \mathrm{~W}$ & N/A & $80 \mathrm{~W}$ \\
PSC1 & {$[1,1,1,0.5]$} & $59,4 \mathrm{~W}$ & $44,01 \mathrm{~W}$ & $59,4 \mathrm{~W}$ \\
PSC2 & {$[1,1,0.5,0.5]$} & $38,4 \mathrm{~W}$ & $41,8 \mathrm{~W}$ & $41,8 \mathrm{~W}$ \\
PSC3 & {$[1,0.5,0.5,0.5]$} & $17,5 \mathrm{~W}$ & $39,9 \mathrm{~W}$ & $39,9 \mathrm{~W}$ \\
\hline
\end{tabular}

N/A: not applicable.

Fig. 2 PV cell equivalent physical circuit 


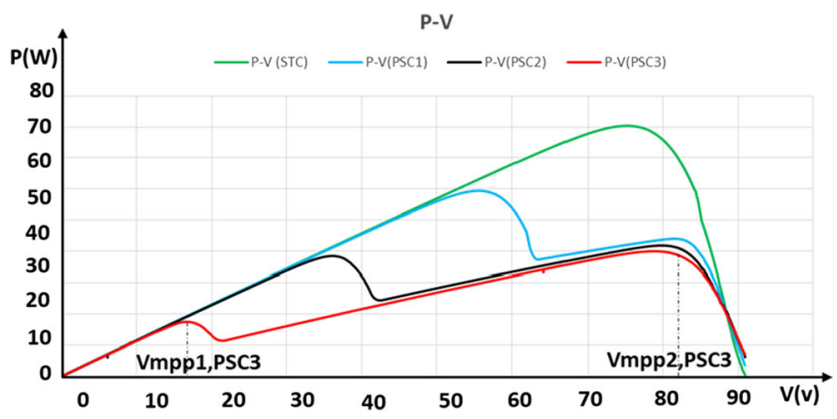

Fig. 3 The P-V curves characteristics of a PV String under diverse irradiation

\section{Methodology}

\section{Description of the Entire PV System}

Figure 1 presents the entire PV system developed in this study, which consist of a PV string, a Boost converter, a GMPPT controller based on the scanning algorithm, and a load. The PV panel used in this work is based on the one-diode model of PV cells $[6,11]$. In addition, the PV cell equivalent physical circuit is depicted in Fig. 2.

$I_{c}=I_{p h c}-I_{0}\left(\exp \frac{q\left(V_{c}+R_{s c} I_{c}\right)}{a K T}-1\right)-\frac{\left(V_{c}+R_{s c} I_{c}\right)}{R_{s h c}}$

The output current of the PV cell is presented by Eq. (1) [6], where $\mathrm{Vc}$ is the input voltage of the PV cell, Io is reverse cell saturation current, Iphc is the input current of PV cell, $\mathrm{K}$ is the value of the Boltzmann's constant $\left(\mathrm{k}=1.3807^{*} 10-23 \mathrm{JK}-1\right)$. $\mathrm{q}$ is the value of the electronic charge $(\mathrm{q}=1.60221019 \mathrm{C})$, And $a$ is the quality factor of the diode.

The reverse cell saturation current $\mathrm{I}_{0}$ represents by Eq. (2)

$I_{o}=I_{o c}\left(\frac{T}{T_{r}}\right)^{3} \exp \left(\frac{q E_{G O}}{G K}\left(\frac{1}{T_{r}}-\frac{1}{T}\right)\right)$

The input current of PV cell $\mathrm{I}_{\text {phc }}$ represents by Eq. (3)

$I_{p h c}=\left[I_{s c}+K_{1}(T-298,18)\right] \frac{G}{1000}$

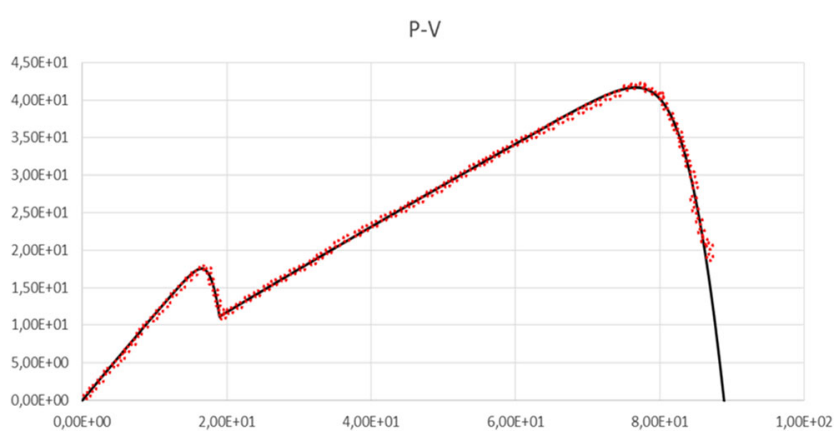

Fig. 4 The scan points on the P-V curves Under PSC3 using the classical scanning method

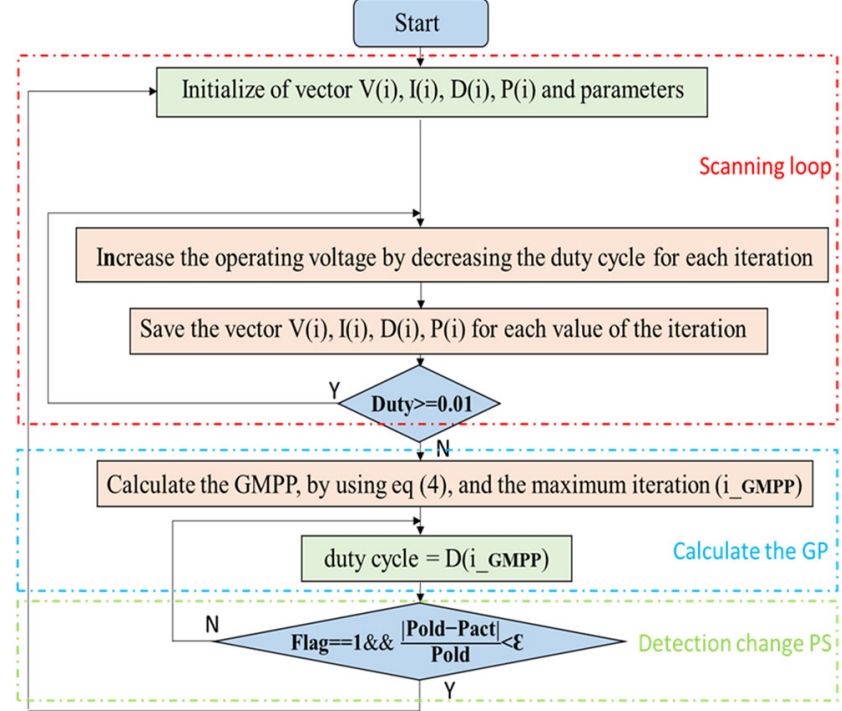

Fig. 5 Flowchart of the proposed scanning method

Table 1 presents the values of the irradiation taken for all simulation tests. Under PSC1, the shading scenarios was performed with the irradiation value of three PV panels set to $1000 \mathrm{~W} / \mathrm{m}^{2}$ and one PV panel set to $500 \mathrm{~W} / \mathrm{m}^{2}$. Thereafter, the shading of the other test is taking by varying the number of the shaded panels of the PV string. Otherwise, the temperature value of module PVs was fixed to $25^{\circ} \mathrm{C}$ in all test simulations of PSCs.

Figure 3 presents the P-V characteristics under the various conditions of irradiation. During PSC, the P-V characteristic of a PV string mainly exhibits two peaks resulting from the presence of two irradiance levels, one is the GP and represents the GMPP of the PV string and the other is the local peak. In addition, the first peak is delivered at Vmpp1 (voltage corresponding to this peak) and the other at Vmpp2. It is assumed that the scan of the P-V characteristic under PSC3 is included a max search interval of search points. For that, the analysis of the classical and the improved scanning methods is based on the P-V characteristic under PSC3.

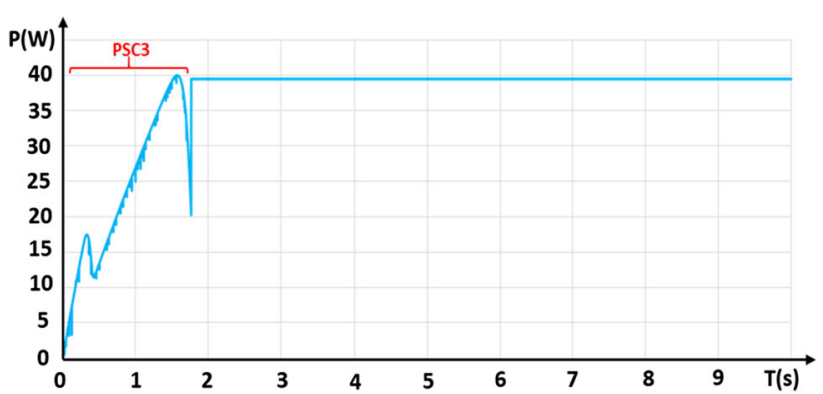

Fig. 6 The output power of the PV string under PSC3 by using the classical scanning method 


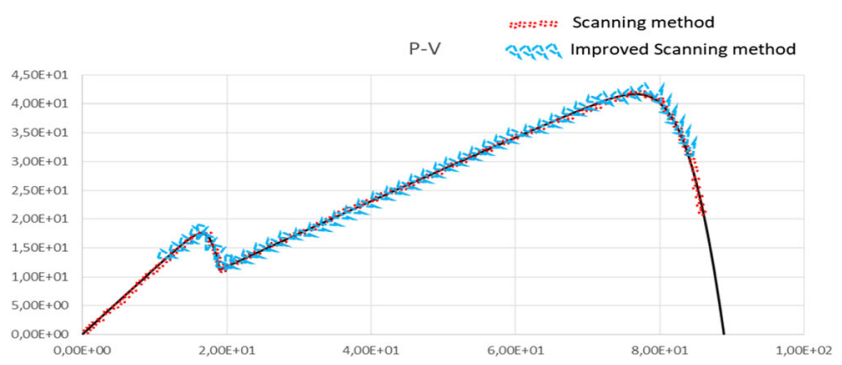

Fig. 7 The scan points on the P-V curves Under PSC3 using the classical and Improved scanning method

\section{Analyse of Classical and Improved Scanning Method for PV System under PSC}

\section{Classical Scanning Method}

The principle of the scanning GMPPT technique is based on the scan of the curve P-V characteristic in order to find the global power of the PV system using simple instructions. When the duty cycle is varied, the value of $\mathrm{V}, \mathrm{I}, \mathrm{P}$, and $\mathrm{D}$ are stored in own vectors at each iteration. Next, it controls the converter by the corresponding value of the global duty cycle in order to maintain the out power of the PV system at the maximal value under various PSCs. Figure 4 presents the scan interval points on the $\mathrm{P}-\mathrm{V}$ curve using the classical scanning method. It is observed that the scanning of the P-V characteristic starts from the point of the short-circuit current (ICC) which corresponds to $0 \mathrm{~V}$ and stops at $0.95 \times$ Voc.

Figure 5 depicts the proposed method's sequence, which consists of three steps. The first step is the scanning loop which contains the data backup of the vectors $\mathrm{D}(\mathrm{i}), \mathrm{P}(\mathrm{i})$, $\mathrm{V}(\mathrm{i}), \mathrm{I}(\mathrm{i})$, obtained in each iteration when the duty cycle is varied. Next, the second step consists of the determination of the GP using Eq. (4) [37]. It is noted that GP of the P-V Characteristics is the maximum value between all the values of P (i) recorded. And the last step is the boucle of detection change PSC.

$\mathrm{GMPP}=\operatorname{Max}(\mathrm{P}(\mathrm{i}))$

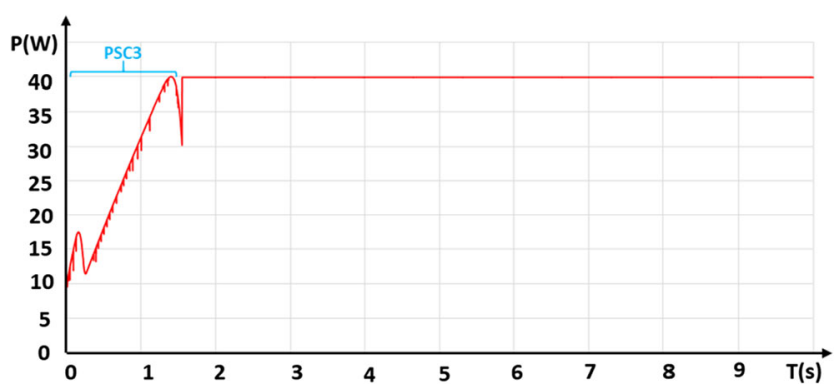

Fig. 8 The output power of the PV string under PSC3 by using the improved scanning method
Figure 6 presents the output power of the PV string under PSC 3 by using the classical scanning method. From this first test, it is observed that the scanning method finds the GMPP with good efficiency and a response time is almost equal to $1.95 \mathrm{~s}$. But, the drawback of this method is the short circuit of the PV string during the scan interval when each PSC change. This, of course, affects the efficiency of the PV array in long term.

\section{Improved Scanning Method}

Figure 7 presents the search interval of the scan points on the $\mathrm{P}-\mathrm{V}$ curves under PSC3 using the classical and improved scanning method. It is observed that the improved scanning method being less scan interval compared to the classical method. The idea of this method is to estimate the scan interval by limiting the search interval of duty ratio. This limitation is giving by some analysis based on PV characteristics as mentioned in Fig. 3. The first step does not start the scan with a short-circuit. In addition, the value of Vmpp2 (voltage corresponding to the second peak) does not exceed the value 0.85 $\times$ Voc. Therefore, we force the improved scanning method to stop at the value of $0.85 \times$ Voc. So, we will win time to extract the GMPP due to limiting the search interval of the $\mathrm{P}-\mathrm{V}$ curve.

Figure 8 illustrates the result of the simulation under PSC3. it is observed that the output power of the PV string is equal to the value of the GP. The irradiation value of each PV model is presented in Table 1. It can be observed that a scan of the P-V curve by the improved scanning method does not start with a short-circuit and stops at the value of $0.85 \times$ Voc. So, This modification improved the response time (1,4 $\mathrm{s})$ compared to the classical scanning method (1,95 s).

\section{Results and Discussion}

The global schematic of the PV system designed in the proteus environment is presented in Fig. 9. The PV string used is composed of six PV panels having the same characteristics. Next, the value of the load is designed by considering the value of the load optimal of the PV string. The DC-DC boost converter is used in order to implement the improved scanning GMPPT. The control of this converter is done through the TC4420 driver. The role of this driver is to boost the value of the duty cycle between a threshold to attack the transistor. The simulation results of the proposed method are displayed in the graphic analysis as shown in Fig. 9.

The simulation results of the improved scanning method are shown in Fig. 10 under various PSCs. The PV string is subjected to different PSCs (PSC1, PSC2, PSC3, and STC). The irradiation value of the PV module for each PCS is taken in Table 1. As mentioned in Fig. 10, the tracking speed with 

Implementation of improved GMPPT based on Scanning method Under Various PSC Author: CHALH abdelilah

\section{Email: abdelilah.chalh@usmba.ac.ma}
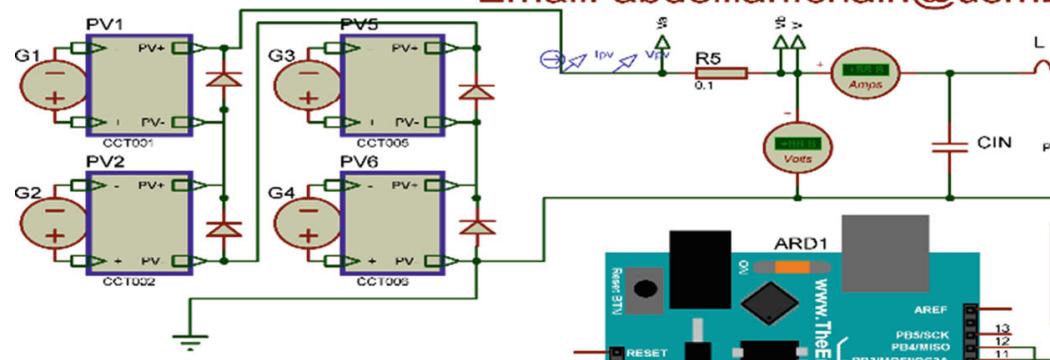

เmำ
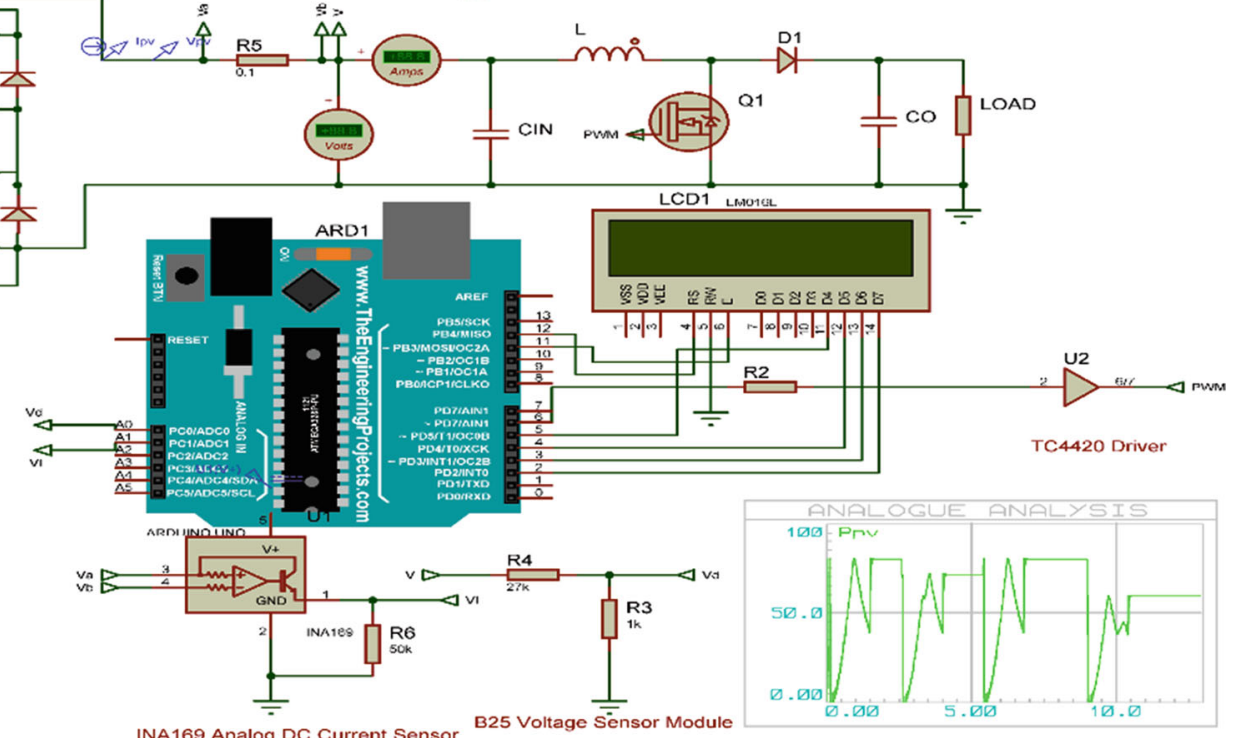

Fig. 9 The global schematic of the PV system designed in the proteus environment

Table 2 Comparisons of classical and modified scanning methods under various PSCs

\begin{tabular}{|c|c|c|c|c|c|c|}
\hline \multirow[t]{2}{*}{ MPPT Algorithms } & \multicolumn{2}{|l|}{ PSC1 } & \multicolumn{2}{|l|}{$\mathrm{PSC} 2$} & \multicolumn{2}{|l|}{ PSC3 } \\
\hline & Efficiency & Response Time & Efficiency & Response Time & Efficiency & Response Time \\
\hline Scanning method [37] & $98.49 \%$ & $1.95 \mathrm{~s}$ & $98.08 \%$ & $1.95 \mathrm{~s}$ & $99.24 \%$ & $1.95 \mathrm{~s}$ \\
\hline Modified Scanning & $98.89 \%$ & $1.4 \mathrm{~s}$ & $98.08 \%$ & $1.4 \mathrm{~s}$ & $99.50 \%$ & $1.4 \mathrm{~s}$ \\
\hline
\end{tabular}

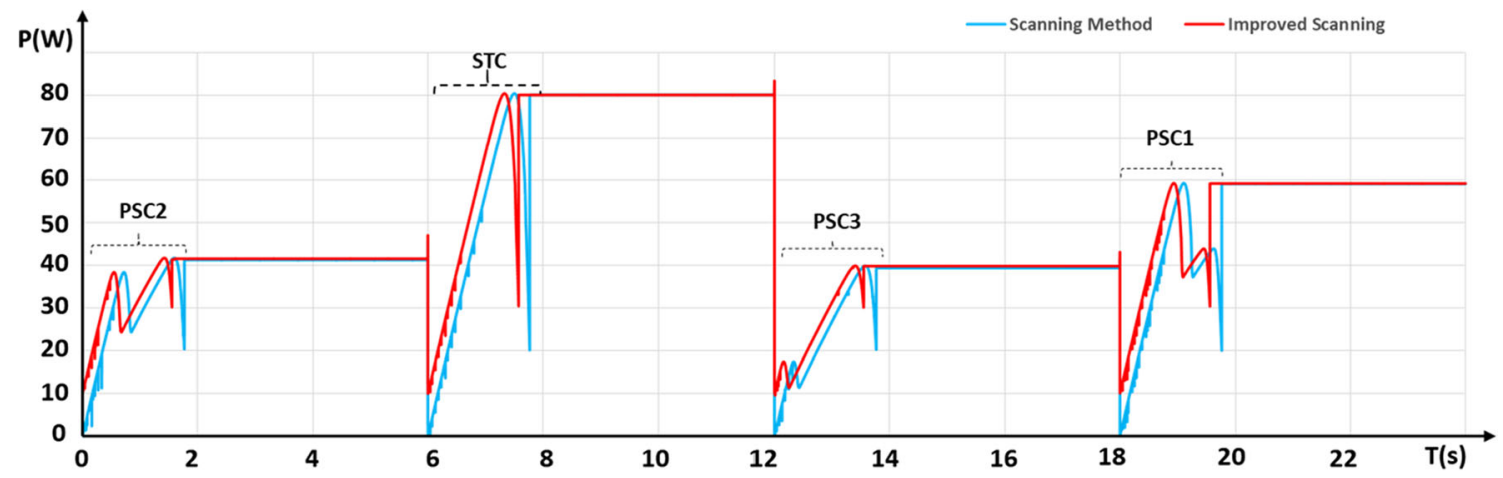

Fig. 10 The output power of the PV string Under Varoius PSCs 


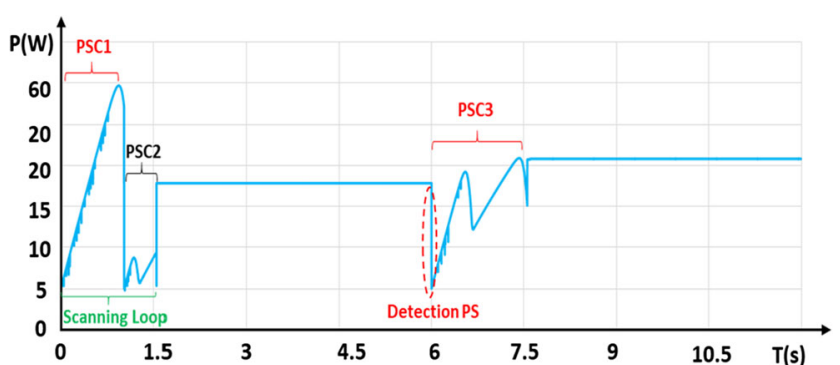

Fig. 11 The results simulation of the output power of the PV string under a change of the insolation value during the scanning loop

the improved method is faster than that of the classical scanning algorithm. To clarify more, the proposed method only takes $1.4 \mathrm{~s}$. Thus, the tracking speed of the improved method is 1.39 times faster than that of the classical scanning method. Also, we can be observed the same conclusion under all PSCs with a fast response time than that of the classical scanning. Furthermore, a comparison between the classical and Improved scanning algorithms is done in Table 2. The first test case under PSC1 presents a good efficiency (98.89\%) and speed response time $(1.4 \mathrm{~s})$. In other's cases, it is obtained the same response time $(1.4 \mathrm{~s})$ compared with the first test. With a maximum efficiency up to $99.50 \%$. from this comparison, can be deduced in all test cases that the efficiency and the response time of the PV system are improved by $0.4 \%$ and 0.55 s respectively compared to the Scanning method [37].

Although the proposed method is simple and easy to implement in low-cost microcontrollers. But, under a change of the insolation value during the scanning operation, this proposed method is unable to track a real GMMP as shown in the results obtained in Fig. 11. On the other hand, when the PSCs change again on the outside of the scanning loop, this method is able to restart the scan in order to track the corresponding GMPP of the PV string. So, it can be used in commercial MPPT controllers in order to increase the energy production of the PV string under PSC while decreasing the cost of the system.

\section{Conclusions}

In this paper, a simple GMPPT controller based on an improved scanning method is proposed. The idea of this improvement is initiated by analyzing the scan interval points on the P-V curve using a conventional scan method. Then, with the analysis based on PV characteristics, we could estimate the scan interval by limiting the search interval of the duty cycle, and thus improve the tracking speed. The obtained results showed that the proposed method efficiently tracks the GMPPT under different CSPs and has a good response time (1.4 s), which improves the response time of the PV system by $0.55 \mathrm{~s}$ compared to the conventional scanning method [37]. Thus, the simple structure used in this proposed method will significantly reduce the implementation complexity, which will lead to a reduction in the cost of the PV system. Although the proposed method is simple and easy to implement in low-cost microcontrollers, it has a limitation in terms of tracking the actual GMPP when a change in the insolation value, during the scan operation, occurs.

Based on the results presented in this paper, the next step of our research will focus on solving the problem of the proposed method's inability to track the actual GMPP during a change in the insolation value.

\section{References}

1. Cantoni R, Rignall K (2019) Kingdom of the sun: a critical, multiscalar analysis of Morocco's solar energy strategy. Energy Res Soc Sci 51:20-31

2. Ahmadi MH, Ghazvini M, Sadeghzadeh M, Alhuyi Nazari M, Kumar R, Naeimi A, Ming T (2018) Solar power technology for electricity generation: a critical review. Energy Sci Eng 6(5):340 361

3. Allouhi A, Kousksou T, Jamil A, El Rhafiki T, Mourad Y, Zeraouli Y (2015) Economic and environmental assessment of solar airconditioning systems in Morocco. Renew Sust Energ Rev 50: 770-781

4. Sonawane, V.P., Soni, M.S. and Lad, A.A., 2021. Rooftop solar installations for demand side management-a case study. In IOP conference series: materials science and engineering (Vol. 1116, no. 1, p. 012068). IOP publishing

5. Skoplaki E, Palyvos JA (2009) On the temperature dependence of photovoltaic module electrical performance: a review of efficiency/ power correlations. Sol Energy 83(5):614-624

6. Hammoumi AE, Motahhir S, Ghzizal AE, Chalh A, Derouich A (2018) A simple and low-cost active dual-axis solar tracker. Energy Science \& Engineering 6(5):607-620

7. Rahman MM, Hasanuzzaman M, Rahim NA (2015) Effects of various parameters on PV-module power and efficiency. Energy Convers Manag 103:348-358

8. Ramos-Hernanz J, Uriarte I, Lopez-Guede JM, Fernandez-Gamiz U, Mesanza A, Zulueta E (2020) Temperature based maximum power point tracking for photovoltaic modules. Scientific Reports 10(1):1-10

9. Saad M, El Hammoumi A, El Ghzizal A (2020) The most used MPPT algorithms: review and the suitable low-cost embedded board for each algorithm. J Clean Prod 246:118983

10. Sera D, Mathe L, Kerekes T, Spataru SV, Teodorescu R (2013) On the perturb-and-observe and incremental conductance MPPT methods for PV systems. IEEE J Photovolt 3(3):1070-1078

11. Zhu W, Shang L, Li P, Guo H (2018) Modified hill climbing MPPT algorithm with reduced steady-state oscillation and improved tracking efficiency. J Eng 2018(17):1878-1883

12. Motahhir S, Chalh A, El Ghzizal A, Derouich A (2018) Development of a low-cost PV system using an improved INC algorithm and a PV panel Proteus model. J Clean Prod 204:355365

13. Ramos-Hernanz J, Lopez-Guede JM, Barambones O, Zulueta E, Fernandez-Gamiz U (2017) Novel control algorithm for MPPT with Boost converters in photovoltaic systems. Int $\mathrm{J}$ Hydrogen Energy 42(28):17831-17855 
14. Chalh, A., Motahhir, S., El Hammoumi, A., El Ghzizal, A. and Derouich, A., 2018. A low-cost PV emulator for testing MPPT algorithm. In IOP conference Series: Earth and Environmental Science (Vol. 161, no. 1, p. 012018). IOP Publishing

15. Chalh A, Saad M, El Hammoumi A, El A (2018) Ghzizal, and A. Derouich. "study of a low-cost PV emulator for testing MPPT algorithm under fast irradiation and temperature change." technology and economics of smart grids and sustainable. Energy 3(1):11

16. Chalh A, El Hammoumi A, Motahhir S, El Ghzizal A, Subramaniam U, Derouich A (2020) Trusted simulation using Proteus model for a PV system: test case of an improved HC MPPT algorithm. Energies 13(8):1943

17. R. Bruendlinger, B. Bletterie, M. Milde, and H. Oldenkamp, "Maximum power point tracking performance under partially shaded PV array conditions", in Proc. 21st EUPVSEC, Dresden, Germany,Sept. 2006, pp. 2157-2160

18. Petrone G, Spagnuolo G, Teodorescu R, Veerachary M, Vitelli M (2008 Jun 24) Reliability issues in photovoltaic power processing systems. IEEE Trans Ind Electron 55(7):2569-2580

19. Maghami MR, Hizam H, Gomes C, Radzi MA, Rezadad MI, Hajighorbani S (2016 Jun 1) Power loss due to soiling on solar panel: a review. Renew Sust Energ Rev 59:1307-1316

20. Silvestre, Santiago, and A. Chouder. "Effects of shadowing on photovoltaic module performance." Progress in Photovoltaics: Research and applications 16, no. 2 (2008): 141-149

21. Silvestre S, Boronat A (2009) A. Chouder. "Study of bypass diodes configuration on PV modules". Appl Energy 86(9):1632-1640

22. Dhimish M (2019) Assessing MPPT techniques on hot-spotted and partially shaded photovoltaic modules: comprehensive review based on experimental data. IEEE Trans Electron Devices 66(3): 1132-1144

23. Ahmed J, Salam Z (2015) A critical evaluation on maximum power point tracking methods for partial shading in PV systems. Renew Sust Energ Rev 47:933-953

24. Ahmad R, Murtaza AF, Sher HA (2019) Power tracking techniques for efficient operation of photovoltaic array in solar applications-a review. Renew Sust Energ Rev 101:82-102

25. Motahhir S, Chouder A, El Hammoumi A, Benyoucef AS, El Ghzizal A, Kichou S, Kara K, Sanjeevikumar P, Silvestre S (2020) Optimal energy harvesting from a multistrings PV generator based on artificial bee colony algorithm. IEEE Syst J 15:4137-4144
26. Salam Z, Ahmed J, Merugu BS (2013) The application of soft computing methods for MPPT of PV system: a technological and status review. Appl Energy 107:135-148

27. Chao K-H, Lin Y-S, Lai U-D(2015) Improved particle swarm optimization for maximum power point tracking in photovoltaic module arrays. Appl Energy 158:609-618

28. Eltamaly, Ali M., Hassan MH Farh, and Ahmed G. Abokhalil. "A novel PSO strategy for improving dynamic change partial shading photovoltaic maximum power point tracker". Energy Sources, Part A: Recovery, Utilization, Environ Effects (2020): 1-15

29. Veerachary M, Yadaiah N (2000) ANN based peak power tracking for PV supplied DC motors. Sol Energy 69:343-350

30. Elobaid LM, Abdelsalam AK, Zakzouk EE (2015) Artificial neural network-based photovoltaic maximum power point tracking techniques: a survey. IET Renewable Power Gen 9(8):1043-1063

31. Xu, J., Shen, A., Yang, C., Rao, W. and Yang, X., 2011. ANN based on IncCond algorithm for MPP tracker. In 2011 sixth international conference on bio-inspired computing: theories and applications (pp. 129-134). IEEE

32. Messai A, Mellit A, Guessoum A, Kalogirou SA (2011) Maximum power point tracking using a GA optimized fuzzy logic controller and its FPGA implementation. Sol Energy 85(2):265-277

33. Taheri, H., Salam, Z. and Ishaque, K., 2010. A novel maximum power point tracking control of photovoltaic system under partial and rapidly fluctuating shadow conditions using differential evolution. In 2010 IEEE symposium on industrial electronics and applications (ISIEA) (pp. 82-87). IEEE

34. Qin AK, Huang VL, Suganthan PN (2008) Differential evolution algorithm with strategy adaptation for global numerical optimization. IEEE Trans Evol Comput 13(2):398-417

35. Fan Q, Wang W, Yan X (2019) Differential evolution algorithm with strategy adaptation and knowledge-based control parameters. Artif Intell Rev 51(2):219-253

36. Valdez F, Melin P, Castillo O (2014) A survey on nature-inspired optimization algorithms with fuzzy logic for dynamic parameter adaptation. Expert Syst Appl 41(14):6459-6466

37. Chalh A, Motahhir S, El Ghzizal A, El Hammoumi A, Derouich A (2020) Global MPPT of photovoltaic system based on scanning method under partial shading condition. SN Appl Sci 2(4):1-5

Publisher's Note Springer Nature remains neutral with regard to jurisdictional claims in published maps and institutional affiliations. 